\title{
Foundation for Modular Cloud Logistics
}

\author{
Michael Glöckner ${ }^{1,2}$, Björn Schwarzbach ${ }^{1}$, André Ludwig ${ }^{2}$, and Bogdan Franczyk ${ }^{1,3}$ \\ ${ }^{1}$ Leipzig University, Germany \\ ${ }^{2}$ Kühne Logistics University, Hamburg, Germany \\ ${ }^{3}$ Wrocław University of Economics, Poland \\ \{gloeckner I schwarzbach I franczyk\}@wifa.uni-leipzig.de - andre.ludwig@the-klu.org
}

\begin{abstract}
Logistics service providers are facing the need to collaborate because of ongoing trends like outsourcing and concentration on core competencies. The paradigm of cloud logistics promises to make collaboration in the logistics domain more easy and more flexible by adopting the principles of cloud computing to the logistics domain. To ensure the success of cloud computing to the paradigm of cloud logistics as well, standards have to be developed. With the help of the service blueprinting method, a basic logistics module is developed in order to lay a foundation for cloud logistics.
\end{abstract}

\section{INTRODUCTION}

$\mathbf{L}$ OGISTICS is affected by increasing outsourcing and thus a concentration on core competencies [1]. Hence, to create sophisticated supply chains and meet complex customer demands, the specialized logistics service providers (LSP) are compelled to work together and collaborate. Flexibility is a driving factor for the selection and orchestration of LSP [2], [3], [4]. Within this context, different paradigms arise and can be adopted to the logistics domain, i.e. service oriented architecture (SOA) paradigm [5], [6] on the one hand and on the other hand the principles of cloud computing (CC) [7], [8]. On the one hand this comprises encapsulation, composability, loose coupling, and reusability (adapted from SOA) and on the other hand virtualization, ad-hoc reconfiguration and interconnectability of resources (adapted from CC). The adoption of cloud principles to the logistics domain to the most possible extent leads to the idea of cloud logistics presented in the discussionpaper of [9].

Cloud logistics (CL) is still a topic in its infancy but bears a lot of potential for the digitization of especially small and medium sized enterprises (SME) in the logistics industry. However, those logistics SME 'refuse' to adopt new technologies [10]. As CC is successfully adopted in a genral way in industry, the adoption of its success factors are a promising way to foster CL. Built upon certain standards of descriptions and interfaces, the success of $\mathrm{CC}$ relies on compatibility and a high usability for customers as background processes are kept hidden and resources (i.e. infrastructure, platform, software) are offered 'as-a-Service' to the customer. Consequently, providers are compatible, ease of use is enabled, costs can be reduced and thus the main objectives of customers are met in order to change their IT to cloud technology [11]. To

The work presented in this paper was funded by the German Federal Ministry of Education and Research within the project Logistik Service Engineering und Management (LSEM). More information can be found under the reference BMBF 03IPT504X and on the website www.lsem.de. make CL become a success as well, such standards and their advantages are obligatory. Cloud principles are to be adopted to the logistics domain in order to lay the foundation of cloud logistics' success.

Delfmann and Jaekel [9] outline a comprehensive service model based on logistics resources and ensuring compatibility through standardized (data) interfaces as a promising field of research for CL. A basic modular approach for CL could standardize interfaces for a sound flow within supply chains.

The paper answers the question: How can a foundation for cloud logistics be laid in terms of a modular approach? with the help of the following research questions:

- $\mathrm{RQ}_{1}$ : What are suitable service engineering methods for creating generic service modules?

- $\mathrm{RQ}_{2}$ : What is an appropriate basic concept for modular cloud logistics?

The contribution of the paper is a basic modular logistics concept in order to enable cloud logistics. In section II background knowledge is given and the reader is briefly introduced to the basics of cloud logistics and service blueprinting, which is the used method for service engineering. Section III presents the basic module concept of cloud logistics. The paper is concluded by a summary and an outlook in section IV.

\section{BACKGROUND}

\section{A. Method}

As cloud logistics is currently a theoretical concept [9], empirical observations are not possible. Thus, a procedure based on the design-science paradigm for information systems [12] is applied. The analysis is conducted during the current section, where the basic principles of cloud logistics are described and later taken as the starting point for the design phase. As cloud logistics focuses especially on the flow of physical as well as informational entities, concepts and methods of product service systems, service blueprinting in particular, are invoked during the design phase. [13] deliver a seminal work reviewing the "State of the art and research challenges of Product-Service Systems Engineering". Further, the method of domain engineering [14] is taken into account in order to find 'common points' and 'varying points', and to create configurable requirements and architecture of the logistics domain. 


\section{B. Cloud Logistics}

Delfmann and Jaekel present the basic idea of cloud logistics (CL) in their discussion paper about the logistics for the future [9]. They cite the German Logistics Association (BVL 2012) [15] and define CL as:

An environment of 'virtual' systems that facilitate supply chains' overall coordination and use of distributed resources, capacities, processes, and services from supply chain partners. These systems are based on advanced information and communication technologies that leverage modern Internet services.

Delfmann and Jaekel mention that the adoption of the cloud principles to other domains does not mean to implement cloud computing solutions in the target domain (however, cloud computing indeed helps to manage and support cloud principles in terms of information systems technology). Rather they emphasize explicitly that the adoption of cloud principles to another domain aims at interpreting the domain itself with the help of a cloud paradigm. With regards to the definition of cloud computing [7], [8], this comprises a pool of virtualized resources, which are easily usable and accessible. The resources offer the possibility of a dynamic (re-)configuration and an adjustment to differing workload. By using same the resources for several customers, an optimal resource allocation and utilization can be achieved. The resources of the network are accessible on demand with minimal management effort 'as-a-Service'.

The interpretation of cloud principles in the logistics domain leads to the paradigm of 'cloud logistics', 'Logisticsas-a-Service' (LaaS) [16], or 'Supply Chain as a Service' (SCaaS) [17]. Core of the idea is to define a new service type next to Infrastructure-as-a-Service, Platform-as-a-Service and Software-as-a-Service. Involved resources of logistics are hidden behind a common predefined interface and can be added, reconfigured and removed 'on-demand' responding to customers' needs [17]. However, reaction times are of course higher, as resource allocation (e.g. transferring trucks to pick up goods) implies the overcoming of physical distances. As competitors now offer more and more homogeneous services (e.g. transportation, warehousing, packing, track and trace), outsourcing is more and more encouraged [18], as seen in other industries before [19]. This process makes it possible to turn fix costs into variable costs [20], as needed logistics services (e.g. transportation, picking) and resources (e.g. trucks, warehouses) can be ordered on demand and thus, logistics assets do not have to be owned directly. Service levels are also well known in logistics [21].

So, just old wine in new skins? Of course outsourcing and insourcing of capabilities, processes and resources is nothing new to logistics. However, with a shift from being rather closed and striving for competitiveness only by low prices, LSP should understand the disruptive paradigms of the cloud and digitization with their inherent transparency and flexibility as a chance. With the adoption of this mindset, the focus could be transferred to an increasing specialization and providing higher service quality in order to be successful on the market.

\section{Service Blueprinting}

Whereas services in logistics are traditionally related to classical business service on the one hand, services in $\mathrm{CC}$ on the other hand are related to electronic services. In order to establish a cloud logistics paradigm, real-world business service and electronic service have to be combined. Usage of service engineering methods for product-service systems (a comprehensive overview can be found in [13]) seems to be appropriate. The method of service blueprinting [23], especially the modified version extended service blueprinting by [22], offers suitable aspects to describe services that are based on both business services electronic services. Figure 1 presents the extended service blueprinting using BPMN.

Hara et al. [22] distinguish between a behavior blueprint that represents the machines and their related software involved in a service (= electronic services) as well as an activity blueprint that represents the 'humanware' and their related supporting software (= business services). General depiction method is the business process management notation (BPMN) in order to ensure a common and easily understandable communication standard. Services in general are seen as a set of functions that have a possible value for customers in terms of changing one or more receiver state parameters (RSP) [24], [25]. Those RSP could be structured down to the lowest level where they represent basic functions and are mapped afterward to specific process steps of services in order to highlight their importance in the context of interaction with the customer. The change of the RSP is goal of business activities and thus they form the input, output and requirements from the stakeholders' sides. Further, two important lines are introduced: the line of interaction (separating service consumers and service providers) and the line of visibility (separating 'onstage (visible)' and 'backstage (invisible)' activities performed by the provider). An inter-relation between the activity blueprint (humanware + related software) and the behavior blueprint (machines + related software) is obligatory for the extended service blueprinting. A connection is to be established between the functions of the RSP and the appropriate process steps.

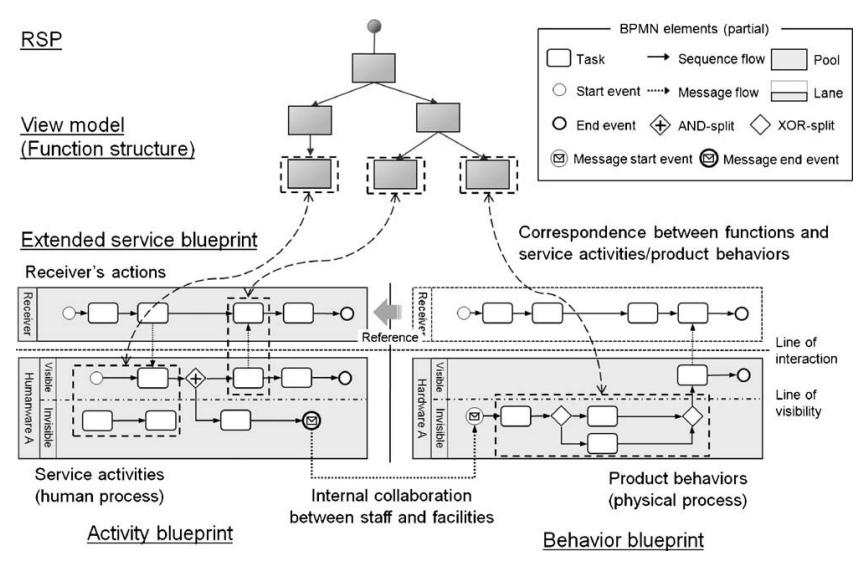

Fig. 1. Notation of the extended service blueprint taken from Hara et al. [22]. 


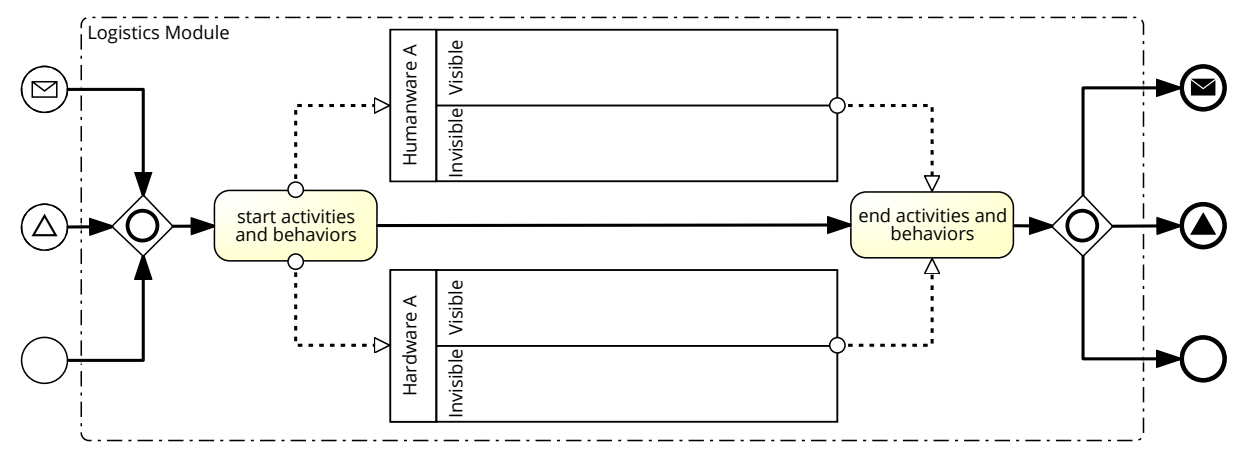

Fig. 2. The extended service blueprint is encapsulated with logistics interfaces in order to create the basic logistics module and enable cloud logistics.

\section{BAsic Logistics Module}

\section{A. Transferring the Extended Service Blueprinting to Logistics}

When creating a basic logistics module, which is based on the extended service blueprinting, the concept shown in Figure 1 has to be encapsulated and logistics characteristics have to be taken into account. From the basic logistics module, specific logistics services can be derived that incorporate distinct logistics resources in order to fulfill logistics functions. Because of the modules with common interfaces, those logistics functions can be combined and thus cloud logistics is enabled.

Common points of logistics are the general planning, operating and controlling of both the flow of goods and the flow of information [26]. The encapsulation is depicted in Figure 2. The activity blueprint (aka. Service activities or human process) as well as the behavior blueprint (aka. product behavior or physical process) are triggered by events. Those events are in every case a distinct trigger-signal (interface middle-event) from the orchestration of the central integrator and the required information (interface top-event) from the central integrator as well as from the previous logistics module. Further, the goods that are involved in the logistics service and their physical allocation (interface bottom-event) are an important input for every logistics module. Those two kinds of events form the common points of the logistics domain. However, cloud logistics is information intensive and comprises also informationcentric services (e.g. customs clearance, identification or track and trace). Hence, as the allocation of physical goods is not always obligatory for information-centric services, an inclusive gateway is chosen to bundle the input flows, or to distribute the output flows, respectively. This is a varying point for services of the logistics domain. With the final output of information, parameters of service quality as well as the trigger-signal for the next logistics module (if existant) can be forwarded. The flow of value in terms of financial aspects is also involved in logistics but not explicitly depicted. On the one hand it is not in the main focus of logistics, and on the other hand it could be regarded as a kind of informational flow in the context of online banking (even though, there are much higher formal and security requirements).
The RSP are the connection to several stakeholders (logistics integrator, logistics service providers and customers) and have to be taken into account as they are goal, input, output and requirements. With the standard of the interface containing three events as input and output, several logistics modules can be put into a (complex) chain in order to connect several logistics resources enabling cloud logistics.

\section{B. Example}

Typical activities of contract logistics are taken from [2]. The rough example comprises a transportation process involving different modes of transport that are carrying hazardous goods, as depicted in Figure 3. Hence, four different logistics modules are to be combined, whereas each module could be sourced from a different LSP. The highest priority is the qualification of having the permission of Hazardous Goods Management. This implies next to specific licenses the ability of monitoring and controlling those hazardous goods. The different modes of transport require an overarching module of Intermodality Management. Its function is the initiation, monitoring and controlling of different modes of transport as well as managing the handling processes between them. Furthermore, the two modes of transport are each invoked through a logistics module. The Rail Transportation is the long-distance run. After finishing, the hazardous goods are

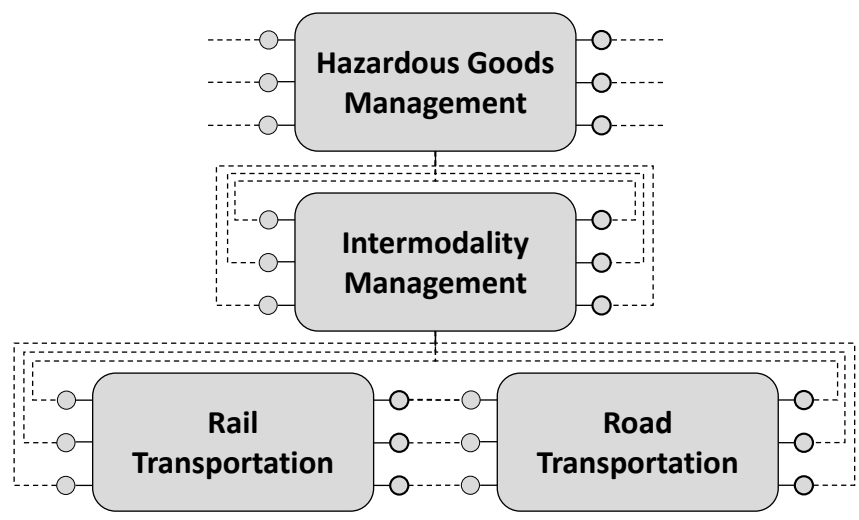

Fig. 3. Logistics Modules of basic logistics functions are combined and invoke other modules in order to develop and operate a complex logistics service. 
loaded from the train to a truck and the Road Transportation is conducted for the short-distance run on the last-mile.

The highest priority module (hazardous goods management) is the initial point for the complex logistics service. During planning phase the connection to the other modules is established and RSP are presented to the further invoked modules as input parameters and requirements. This invocation is either done automatically by the hardware lane of the module or manually by the humanware lane (see Figure 2).

\section{CONCLUSION}

In the paper, a brief introduction to cloud logistics is given and the need for standardized logistics modules as an enabler is outlined. In order to answer research question 1 the method of extended service blueprinting is presented as a suitable possibility for designing standardized logistics modules as it enables both human and machine interaction and meeting logistics characteristics of informational and physical flows. In order to answer research question 2 , a basic concept for a logistics service module is presented and applied to a rough example of a complex logistics service. Summarizing, a foundation for cloud logistics is laid in terms of a basic logistics modular approach concept. The modular approach with standardized interfaces enables the access to resources of the logistics network on demand with minimal management effort 'as-a-Service'.

Implication for the scientific community on the one hand is an initial concept of module in order to enable cloud logistics. On the other hand implication for business is to introduce the cloud logistics paradigm as beinng a disruptive force, bringing a high potential for increased flexibility and efficiency for collaborative complex logistics services.

Future fields of research should address the module itself in terms of further developing its details such as the interfaces, formats of information interchange and invoking techniques for nesting and embedding. Another field of interest could be the standardization of the internal logistics transformations of the modules (e.g. [26] describe logistics as a transformation of goods in space and time). With this module-internal standardization, the standardization of the interfaces as well as a categorization of modules can be realized. Prioritization of different modules, as shown in the example, should follow distinct rules, which form another field of future research.

\section{REFERENCES}

[1] J. Langley and M. Long, "2016 third-party logistics study: The state of logistics outsourcing: Results and findings of the 20th annual study," vol. 20,2016

[2] A. Aguezzoul, "Third-party logistics selection problem: A literature review on criteria and methods," Omega, vol. 49, pp. 69-78, 2014. DOI: 10.1016/j.omega.2014.05.009.

[3] T. Solakivi, J. Töyli, and L. Ojala, "Logistics outsourcing, its motives and the level of logistics costs in manufacturing and trading companies operating in finland," Production Planning \& Control, vol. 24, no. 4-5, pp. 388-398, 2013. DOI: 10.1080/09537287.2011.648490.

[4] R. Wilding and R. Juriado, "Customer perceptions on logistics outsourcing in the european consumer goods industry," International Journal of Physical Distribution \& Logistics Management, vol. 34, no. 8, pp. 628-644, 2004. DOI: 10.1108/09600030410557767.
[5] A. Arsanjani, G. Booch, T. Boubez, P. Brown, D. Chappell, J. deVadoss, T. Erl, N. Josuttis, D. Krafzig, M. Little, B. Loesgen, A. T. Manes, J. McKendrick, S. Ross-Talbot, S. Tilkov, C. Utschig-Utschig, and H. Wilhelmsen. (2009). Soa manifesto, [Online]. Available: http:// www.soa-manifesto.org/SOA_Manifesto.pdf.

[6] T. Erl, SOA: Principles of service design, 5. print, ser. The Prentice Hall service-oriented computing series from Thomas Erl. Upper Saddle River, NJ [u.a.]: Prentice Hall, 2009, ISBN: 9780132344821.

[7] P. Mell and T. Grance, "The nist definition of cloud computing," Computer Security Division, Information Technology Laboratory, National Institute of Standards and Technology Gaithersburg, 2011.

[8] L. M. Vaquero, L. Rodero-Merino, J. Caceres, and M. Lindner, "A break in the clouds," ACM SIGCOMM Computer Communication Review, vol. 39, no. 1, p. 50, 2008. DOI: 10.1145/1496091.1496100.

[9] W. Delfmann and F. Jaekel, The cloud - logistics for the future? discussionpaper, German Logistics Association - BVL International, Ed., 2012.

[10] U. Arnold, J. Oberlander, and B. Schwarzbach, "Logical—development of cloud computing platforms and tools for logistics hubs and communities," in Computer Science and Information Systems (FedCSIS), 2012 Federated Conference on, 2012, pp. 1083-1090.

[11] P. Gupta, A. Seetharaman, and J. R. Raj, "The usage and adoption of cloud computing by small and medium businesses," International Journal of Information Management, vol. 33, no. 5, pp. 861-874, 2013. DOI: 10.1016/j.ijinfomgt.2013.07.001.

[12] A. Hevner, S. March, J. Park, and S. Ram, "Design science in information systems research," MIS Quarterly, vol. 28, no. 1, pp. 75-105, 2004.

[13] S. Cavalieri and G. Pezzotta, "Product-service systems engineering state of the art and research challenges," Computers in Industry, vol. 63, no. 4, pp. 278-288, 2012. DOI: 10.1016/j.compind.2012.02.006.

[14] K. Czarnecki and U. Eisenecker, Generative programming: Methods, tools, and applications. Boston: Addison Wesley, 2000, ISBN: 0-20130977-7.

[15] German Logistics Association. (2012). 6th international scientific symposium on logistics: Call for papers, [Online]. Available: http://www. bvl.de/misc/filePush.php?id=15746\&name=ISSL12+Call+for+Papers

[16] K. Klingebiel and A. Wagenitz, "An introduction to logistics as a service," in Efficiency and logistics, ser. Lecture Notes in Logistics, U. Clausen, M. ten Hompel, and M. Klumpp, Eds., Springer, 2013 , pp. 209-216, ISBN: 978-3-642-32837-4. DOI: 10.1007/978-3-64232838-1_22.

[17] J. Leukel, S. Kirn, and T. Schlegel, "Supply chain as a service: A cloud perspective on supply chain systems," IEEE Systems Journal, vol. 5 , no. 1, pp. 16-27, 2011. DOI: 10.1109/JSYST.2010.2100197.

[18] T. H. Davenport, "The coming commoditization of processes," Harvard business review, vol. 83, no. 6, pp. 100-108, 2005.

[19] M. Reimann, O. Schilke, and J. S. Thomas, "Toward an understanding of industry commoditization: Its nature and role in evolving marketing competition," International Journal of Research in Marketing, vol. 27, no. 2, pp. 188-197, 2010. DOI: 10.1016/j.ijresmar.2009.10.001.

[20] P. Matthyssens and K. Vandenbempt, "Moving from basic offerings to value-added solutions: Strategies, barriers and alignment," Industrial Marketing Management, vol. 37, no. 3, pp. 316-328, 2008. DOI: 10. 1016/j.indmarman.2007.07.008.

[21] J. T. Mentzer, D. J. Flint, and J. L. Kent, "Developing a logistics service quality scale," Journal of Business Logistics, vol. 20, no. 1, p. 9, 1999.

[22] T. Hara, T. Arai, Y. Shimomura, and T. Sakao, "Service cad system to integrate product and human activity for total value," CIRP Journal of Manufacturing Science and Technology, vol. 1, no. 4, pp. 262-271, 2009. DOI: 10.1016/j.cirpj.2009.06.002.

[23] L. G. Shostack, "How to design a service," European Journal of Marketing, vol. 16, no. 1, pp. 49-63, 1982.

[24] T. Sakao and Y. Shimomura, "Service engineering: A novel engineering discipline for producers to increase value combining service and product," Journal of Cleaner Production, vol. 15, no. 6, pp. 590-604, 2007. DOI: 10.1016/j.jclepro.2006.05.015.

[25] T. Arai and Y. Shimomura, "Proposal of service cad system - a tool for service engineering -," CIRP Annals - Manufacturing Technology, vol 53, no. 1, pp. 397-400, 2004. DOI: 10.1016/S0007-8506(07)60725-2.

[26] T. Gudehus and H. Kotzab, Comprehensive Logistics. Berlin, Heidelberg: Springer Berlin Heidelberg, 2012, ISBN: 978-3-642-24366-0. DOI: $10.1007 / 978-3-642-24367-7$ 